\title{
GÓMEZ-TORRENTE ON REFERENCE TO ORDINARY SUBSTANCES ${ }^{1}$
}

\author{
Martín Abreu Zavaleta \\ https:/ / orcid.org/0000-0002-5784-7953 \\ Umea University \\ Department of Historical, Philosophical and Religious Studies \\ Umeå \\ Sweden \\ martin.abreu@umu.se
}

\begin{abstract}
Article info
CDD: 401

\section{Keywords \\ Reference \\ Natural kind terms}

Received: 19.07.2020; Accepted: 15.08.2020

https://doi.org/10.1590/0100-6045.2020.V43N4.MX

Abstract: According to the Kripke-Putnam orthodoxy, a term like 'water' refers to samples of the same substance as the items on the basis of which the term was introduced. However, observations due to Needham (2000) and Leslie (2013) cast doubt on the idea that there is a uniquely privileged notion of substance relevant to the determination of reference, in which case it would seem at best indeterminate what the word 'water' refers to. In response to this problem, Gómez-Torrente (2019) has argued that there is a privileged notion of substance that plays a role in the determination of reference, namely, the ordinary notion of substance. This paper argues that Gómez-Torrente's proposal is not successful. Contrary to what Gómez-Torrente supposes, there

\footnotetext{
${ }^{1}$ For helpful discussion, thanks to Axel Barceló, Thainá Coltro Demartini, Ricardo Mena, Mario Gómez-Torrente, Eleonora Orlando, Melisa Vivanco. Thanks especially to Erica Shumener for helpful comments on earlier versions of this note.
} 
is no uniquely privileged ordinary notion of substance; rather, there are many notions of substance compatible with the meaning of 'substance' none of which seems privileged over the rest.

1. According to the Kripke-Putnam orthodoxy, there are two main ways in which a term like 'water' can come to refer to something in a given speaker's mouth. One way is for the speaker to inherit the term 'water' from someone in whose mouth 'water' refers to something, and for the speaker to intend to refer with 'water' to whatever the person from whom she inherited the term referred to. Another way is for the speaker to intend to refer with 'water' to any sample of the same substance as certain perceptually or descriptively available items (e.g. samples of water).

An important problem for the Kripke-Putnam orthodoxy is that there does not seem to be a single privileged notion of substance that is relevant to the determination of reference. Consider for example Kripke and Putnam's view that two items are samples of the same substance just in case they have the same chemical structure. In particular, to use one of Kripke and Putnam's favorite examples, a certain liquid is the same substance as water just in case it is $\mathrm{H}_{2} \mathrm{O}$.

The problem with this characterization is that there are two spin-isomers of $\mathrm{H}_{2} \mathrm{O}$ (Needham 2000; Leslie 2013): orthowater, in which the nuclear spins of the two hydrogen atoms are aligned parallel, and parawater, in which the two proton spins are aligned antiparallel. By some accounts, such as the entropy of mixing test, orthowater and parawater count as different substances, while by others, such as the phase rule test, they count as the same (See Leslie 2013). Furthermore, while typical water has a $3: 1$ ratio of orthowater to parawater, orthowater and parawater are in 
principle separable (though each quickly returns to a combination of orthowater and parawater). Given these considerations, should we say that a certain sample is the same substance as water just in case it is either one of orthowater or parawater? Just in case it is orthowater? Just in case it is a mixture with a $3: 1$ ratio of orthowater to parawater? None of these criteria would seem to be privileged over the rest, in which case it would seem to be at least indeterminate what the word 'water' refers to. This is the problem of arbitrariness.

2. As part of his excellent and insightful discussion on the reference of natural-kind terms, Gómez-Torrente argues that there is a privileged notion of substance that plays a role in the determination of reference, namely, the ordinary, prescientific notion of substance. One way of reconstructing the argument goes as follows (See Gomez-Torrente 2019, pp. 174ff.). Suppose that there is a substance that 'water' refers to; i.e., water. Because typical samples of water are made of $3 / 4$ orthowater and $1 / 4$ parawater, neither being parawater nor being orthowater are sufficient for being water. Thus, water is neither water nor orthowater. Nor should we think that water is the substance made of $3 / 4$ orthowater and $1 / 4$ parawater. For it is conceivable that the orthowater in typical samples of water belongs to yet another subkind of orthowater, OW1, to be distinguished from the subkind of orthowater OW2. In that case, typical samples of water would be made of $3 / 4$ OW1 and $1 / 4$ parawater; thus, since something may be $3 / 4$ orthowater and $1 / 4$ parawater by virtue of being $3 / 4$ OW2 and $1 / 4$ parawater, being $3 / 4$ orthowater and $1 / 4$ parawater is not sufficient for being water. Hence, being water is not the same as being $3 / 4$ orthowater and $1 / 4$ parawater. 
More generally, Gómez-Torrente surmises, there is no substance specifiable using only precise vocabulary from chemistry which water is identical to. Thus, according to Gómez-Torrente, if the term 'water' refers at all, it can only refer to the substance water, a sui generis substance which can't be fully characterized using only chemical vocabulary. Accordingly, because no chemically specifiable notion of substance seems especially fit for determining the reference of 'water', we should think that the notion of substance relevant to determining the referent of 'water' is the ordinary notion of substance - the notion of substance according to which water is a substance in its own right, irreducible to any chemically specifiable substance. In other words, because 'water' can only refer to a substance in the ordinary sense, and 'water' does refer, the privileged notion of substance for the purposes of determining reference must be the ordinary notion of substance.

3. Gómez-Torrente makes a convincing case that the referent of 'water' can't be identified with any one nondisjunctive, chemically specifiable substance. I also agree with his more general conclusion that, if typical substanceterms in natural language refer at all, they do not refer to non-disjunctive, chemically specifiable substances. However, I am skeptical that appealing to the ordinary notion of substance is sufficient to address arbitrariness concerns; as it stands, the ordinary notion of substance is too unregimented to determine a privileged criterion for when two items exemplify the same substance which is uniquely relevant to the determination of reference.

According to Gomez-Torrente (2019), 
in virtue of the notion of substance, the things exemplifying a substance will be the things which are not too different, in a suitably vague sense, from the paradigms as regards the necessary properties of the latter. (p. 179)

For example, if it is a necessary property of certain samples of water that they are composed of $\mathrm{H}_{2} \mathrm{O}$, then the items that exemplify water will be all and only the items similar enough to those samples with respect to the property of being composed of $\mathrm{H}_{2} \mathrm{O}$, among other of the samples' necessary properties. I will refer to the claim in the quoted passage as "GT"s thesis". Below I argue that GT"s thesis can be precisified in many different ways, none of which is privileged over the rest merely by virtue of the content of the ordinary notion of substance. Since those different precisifications yield different criteria for individuating substances, the ordinary notion of substance does not on its own determine a uniquely privileged such criterion.

There are at least two dimensions on which GT's thesis can be precisified. One dimension corresponds to which of the paradigms' properties one should take into account when assessing whether a certain item exemplifies the same substance as the paradigms. Along this dimension, we can identify three general ways of precisifying GT's thesis:

(1a) X exemplifies the same substance as paradigm $\mathrm{Y}$ just in case $\mathrm{X}$ is similar enough to $\mathrm{Y}$ with respect to every necessary property of $\mathrm{Y}$.

(1b) $\mathrm{X}$ exemplifies the same substance as paradigm $\mathrm{Y}$ just in case $\mathrm{X}$ is similar enough to $\mathrm{Y}$ with respect to some necessary property of $\mathrm{Y}$. 
(1c) X exemplifies the same substance as paradigm $\mathrm{Y}$ just in case $\mathrm{X}$ is similar enough to $\mathrm{Y}$ with respect to certain specific necessary properties of $\mathrm{Y} .^{2}$

Another dimension corresponds to the sense in which two objects are similar enough with respect to a certain property. Along this dimension, we can identify two general precisifications:

(2a) X is similar enough to $\mathrm{Y}$ with respect to Y's property $\mathrm{P}$ just in case $\mathrm{X}$ has $\mathrm{P}$.

(2b) $\mathrm{X}$ is similar enough to $\mathrm{Y}$ with respect to $\mathrm{Y}$ 's property $\mathrm{P}$ just in case $\mathrm{X}$ has some property similar enough to P.

Precisifications of GT's thesis can be obtained by combining each way of precisifying GT's thesis along the first dimension with a way of precisifying it along the second one. Is there anything implicit in the ordinary notion of substance which would privilege some combination of the precisifications above over the rest? Presumably not; competent speakers familiar with the notion of substance could reasonably disagree about which precisification one should adopt without thereby being confused about what "substance" means.

That said, there are reasons to prefer some precisifications over others but, importantly, those reasons stem from substantive metaphysical arguments-not from observations about the content of the ordinary notion of

2 Other precisifications would have it that $\mathrm{X}$ must be similar enough to $\mathrm{Y}$ with respect to most, enough, or some similarly vague quantity of Y's necessary properties. Because any given object has infinitely many necessary properties, I take this route to be a nonstarter. 
substance. Furthermore, as we will see, even once we settle on that precisification, no unique, privileged notion of substance is determined.

Consider the precisifications along the first dimension. Precisifications along the lines of (1a) are too constraining. For suppose that one of the paradigms in question is $\mathrm{Y}$. One of Y's necessary properties is that of being identical to $\mathrm{Y}$, but this is not a property that $Y$ shares with any other object, nor is it obvious in what sense an object different from X could have a property sufficiently similar to the property of being identical to $\mathrm{X}$. Thus, if the items that exemplify the same substance as $\mathrm{X}$ are the items that are similar to $\mathrm{X}$ with respect to every one of X's properties, no item other than $\mathrm{X}$ will exemplify the same substance as X. But then, if it is possible that two different items exemplify the same substance, we should reject (1a).

On the other hand, precisifications along the lines of (1b) are too liberal. For example, any given sample of water has the necessary property of being spatially located. But then, since any material object is necessarily spatially located, precisifications along the lines of $(1 \mathrm{~b})$ predict that every material object exemplifies the same substance as water. Provided that different objects can exemplify different substances, this leaves (1c) as the only remaining option along the first dimension.

What about the second dimension? Arguably, according to Gómez-Torrente, (2a) ought to be rejected in favor of (2b). For suppose that one of the necessary properties of paradigms of water relevant to substance exemplification is the property of being composed of $3 / 4$ orthowater and $1 / 4$ parawater. The problem is that there might be items that exemplify water even if they are composed of slightly different ratios of orthowater to parawater-e.g. items composed of $\frac{29}{40}$ orthowater and $\frac{11}{40}$ parawater. Yet, since those items don't have the property of being composed of 
$3 / 4$ orthowater and $1 / 4$ parawater, (2a) predicts that they do not exemplify water. ${ }^{3}$

Given the foregoing observations, the combination of (1c) and (2b) seems preferable over the rest. This gives us the following interpretation of GT's thesis:

Exemplification: The things exemplifying a certain substance are the things $\mathrm{X}$ such that, for every property $\mathrm{P}$ in a certain specific set of necessary properties of the substance's paradigms, X has a property similar enough to P.

Importantly, note that the arguments I have offered in favor of Exemplification are all substantive metaphysical arguments which reasonable, competent users of the word 'substance' could reject. For example, competent users of the word 'substance' could be willing to accept the consequence that, strictly speaking, no two items exemplify the same substance, and therefore be willing to accept a precisification of the notion of substance along the lines of (1a). If they did so, that would be due to their substantive metaphysical views, not to some confusion about the ordinary notion of substance.

\footnotetext{
${ }^{3}$ Following Gómez-Torrente (2019, p. 179), the present argument assumes that being composed of $3 / 4$ orthowater and $1 / 4$ parawater is one of the necessary properties of paradigms of water relevant to determining whether something is the same substance as the paradigms. One can resist the case against (2a) by rejecting this assumption; indeed, nothing in the ordinary notion of substance seems to preclude this strategy.
}

Manuscrito - Rev. Int. Fil. Campinas, v. 43, n. 4, pp. 97-107, Oct.-Dec. 2020. 
4. Though Exemplification considerably sharpens GT's thesis, it does not on its own determine a uniquely privileged criterion for when two items exemplify the same substance. Indeed, it only provides such a criterion given (i) assumptions about which among all the paradigms' necessary properties are the ones that count for the purposes of sameness of substance, and (ii) assumptions about the sense in which two properties are similar enough for the purposes of sameness of substance. Nothing in the ordinary notion of substance or in Exemplification itself determines which particular assumptions to make.

Consider for instance the properties of being composed of $\mathrm{H}_{2} \mathrm{O}$, and of being composed of $3 / 4$ orthowater and $1 / 4$ parawater. Should we take both of those properties to figure in the set of the paradigms' properties relevant to determining whether other items are the same substance as the paradigms? Nothing in the ordinary notion of substance would seem to suggest an answer one way or the other. For all the word 'substance' means, both properties may be relevant, or only one of them may be; if the latter, nothing in the ordinary notion of substance will determine which of the two properties is the relevant one. In fact, for all 'substance' means, it may be that neither property is relevant to determining whether something is the same substance as the paradigm samples; after all, for all the word 'substance' means, it may be that the only relevant property is that of being made of atoms, or even that of being made of the particular matter an object is made of.

Similar problems arise with respect to the relevant notion of similarity. Consider the property of being composed of $3 / 4$ orthowater and $1 / 4$ parawater. Is this property sufficiently similar, in the relevant sense, to the property of being composed of orthowater or parawater? Is it sufficiently similar to being fully composed of orthowater? Furthermore, orthowater and parawater are composed of hydrogen and 
oxygen. Is the property of being composed of $3 / 4$ orthowater and $1 / 4$ parawater sufficiently similar, in the relevant sense, to the property of being composed of hydrogen and oxygen? Once again, it does not seem that mere reflection on the ordinary notion of substance can settle this question. In that case, the ordinary notion of substance alone does not determine a single criterion for when two items exemplify the same substance.

5. I have argued that, contrary to what Gómez-Torrente claims, appealing to the ordinary notion of substance does not solve the problem of arbitrariness. In a way, what my observations show is that there is no single ordinary notion of substance; instead, there are many eligible notions of substance compatible with what 'substance' means in ordinary language. If any one of those notions is privileged over the rest for the purposes of determining reference, that won't be due to the content of the ordinary notion of substance, but to independent reasons, metaphysical or otherwise.

That this is so does not diminish the value of GómezTorrente's work. One of the lessons from his book is that, if terms like 'water' refer to anything at all, they do not refer to any non-disjunctive, scientifically specifiable substance. This is one of the lessons that makes the book a key contribution to the theory of reference.

\section{REFERENCES}

GÓMEZ-TORRENTE, M. Roads to Reference. An Essay on Reference Fixing in Natural Language. Oxford: Oxford University Press. 2019. 
LESLIE, S. J. "Essence and Natural Kinds: When Science Meets Preschooler Intuition." Oxford Studies in Epistemology 4, pp. 108-66. 2013.

NEEDHAM, P. “What Is Water?” Analysis 60 (1), pp. 1321. 2000.

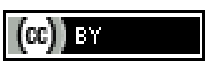

